\title{
Openness Degree of Agric Products, Self-sufficiency Rate of Agric Products and Growth Rate of Agric Output
}

\author{
Shaowen Yang ${ }^{1, a^{*}}$ and Ositanwosu Chukwunonso ${ }^{2,3}$ \\ ${ }^{1}$ Guangdong University of Petrochemical Technology, Maoming, China \\ ${ }^{2}$ South China Agricultural University, Guangzhou, China \\ ${ }^{3}$ Nnamdi Azikiwe University, Awka, Nigeria \\ ayangshaowen69@163.com, ${ }^{\mathrm{b}}$ chynon24@yahoo.com \\ *The corresponding author
}

Keywords: Agric products openness; Self-sufficiency rate; Growth rate; Distribution identities

\begin{abstract}
This paper explored the mechanism of agricultural products opening. The research of the literature showed that the degree of openness of agric products has both direct and indirect influence on the self-sufficiency rate. An increase in the degree of openness of agric-products has a direct negative effect on its self-sufficiency rate. More so, this increase in the degree of openness also have a direct positive effect on the growth rate of agricultural output, and then has an indirect positive effect on the self-sufficiency rate of agric products. This paper used transformation and mathematical derivation of the distribution identities of agricultural products from both the static and dynamic perspective, and proved the mechanism relation derived by mathematical model relations. It helps for a better understanding of the relations elaborated in literature for the agric-products openness, the agric-products self-sufficiency rate and the agric-output growth rate, providing theoretical basis for empirical measurement.
\end{abstract}

\section{Introduction}

In the past 30 years, many scholars have analyzed the impact of openness on China's agriculture. The results observed can be grouped into both positive and negative. Some studies concluded that openness has increased the supply of agric products, improved the allocation of domestic agricultural resources, accelerated agricultural science and technology, promoted the exports of competitive agricultural products, and finally upgraded agricultural development. Others studies observed that in the process of openness, there are most times pitfalls of comparative advantage.

This paper examines the agric products openness $(O P)$, self-sufficiency rate $\left(F_{S}\right)$ and output growth rate $\left(Q r_{A}\right)$ using the theoretical model. It analyzes both negative and positive effect of agric products openness on its self-sufficiency rate.

\section{Literature Review}

It is a common understanding that agricultural products self-sufficiency rate will increase as long as the agricultural output growth rate is more than the population growth rate. Existing literatures are mainly in relations such as openness and growth, openness and self-sufficiency.

Agric Products Openness and Output Growth Rate. Many economists agree that openness can promote economic growth [1], but the promotion to the first, second and third industry is not in the same degree. Since revenue of the second and the third industry are generally higher than agriculture, the excessive outflow of agricultural resources can lead to shrinking of the agricultural economy [2]. According to Huang and Shu (2007), there is no long-term stable relationship between trade openness and real GDP in China [3]. Agricultural opening up in China is mainly for marketing of agricultural products and its effect on openness under the special circumstances is limited [4]. Many scholars believe that by comparative advantage, openness of agricultural products and factors promote effectively the development of China's agricultural economy [5]. For developing country, it also includes making up the shortage of agricultural inputs, promoting progress of agricultural 
science and technology, ameliorating agricultural production conditions and improving the level of agricultural industrialization [6]. However, Wen and Zhuang (2003) argued that the high openness can lead to a risk that China's agricultural resources and market pricing is manipulated by foreign group. This affects industrial safety from three aspects in national agricultural competitiveness, ability to respond to market or natural disasters and future development potential of agriculture [7].

Agric Products Openness and Self-sufficiency Rate. The relationship between agric products openness and self-sufficiency rate is complex. Many scholars agree that higher self-sufficiency rate will result in lower openness [8]. When China's self-sufficiency rate for food is below 90\%, the amount of food imports will seriously affect world grain market. However, other scholars believe that the two sides are not entirely conflicting [9]. Openness will help to get the food from the world market safely, and reduce the pressure of domestic self-sufficiency rate of food [10]. China should carefully handle the relationship, develop strategic measures to cope with food shortages, take advantage of the international market to stabilize domestic food supply and demand fluctuations [5].

In the light of the afore-stated, there are two ways that the agricultural products openness affects the self-sufficiency rate. First is the direct negative impact way which implies that higher agricultural products openness will result in lower self-sufficiency rate. Second is the indirect positive effect way which implies that openness raises agricultural products growth to improve self-sufficiency rate. However, there is no literature on the combination of the two ways yet.

\section{Theoretical Model Analysis}

The direct impact is a static relation that the agricultural products openness affects the self-sufficiency rate, which shows a conflicting relation in a certain period. The indirect impact is a dynamic relation that the openness affects the self-sufficiency rate through the agricultural products growth rate. For China, the two impact approaches move in opposite direction but combine together. The relation between agricultural products openness and its self-sufficiency rate can be conceived as an inverted U curve. Therefore, there may be a moderate range of openness theoretically.

Agricultural output can be used to represent gross agricultural output value which is the total amount of all agricultural products in currencies, reflecting the total size and the total outcomes of agricultural products in a period of time. Its calculation method is that the yield of agriculture, forestry, animal husbandry and fishery products and by-products production are multiplied by the unit price of the respective product and then sum. The gross agricultural products output value can be divided into two parts with domestic consumption and export, namely: the distribution identities of agricultural products represented by the Eq.1:

$$
Q_{A}=C_{A}+T_{E}
$$

Where $Q_{A}$ is the gross agric products output value, $C_{A}$ the domestic consumption and $T_{E}$ the agricultural exports. Both sides of Eq.1 plus agricultural imports, is

$$
Q_{A}+T_{M}=C_{A}+T_{E}+T_{M}
$$

Where $T_{M}$ is the agricultural imports. In the view of market, total domestic demand of agricultural products is the gross agric products output value plus the net difference between agricultural imports and agricultural exports. It can be calculated as Eq.3:

$$
H_{1}=Q_{A}+T_{M}-T_{E}
$$

Where $\mathrm{H} 1$ is total domestic demand of agricultural products.

Agric products self-sufficiency rate is defined as the ratio of the total products output and the total demand of domestic agric products according to most of the literature, so it is expressed as $F s=\frac{Q_{A}}{H_{1}}$. 
Agricultural products openness (OP) herein is defined as the ratio for the sum of agricultural

import and export and the gross agricultural products output value, namely:

$$
O P=\frac{T_{M}+T_{E}}{Q_{A}}
$$

Relation between Agric Products Openness and Self-Sufficiency Rate. From Eq.2 and Eq.3, we obtain

$$
\frac{1}{F_{S}}=\frac{C_{A}-T_{E}}{Q_{A}}+O P
$$

Eq.4 is static, which means on the condition of the certain total amount of products in a period of time, relation between agricultural products openness and self-sufficiency rate is a similar reciprocal. It verifies the issue agreed by most scholars that a higher self-sufficiency rate of agricultural product will result in lower level of openness. Therefore get

Proposition 1: From a static point of view, to increase agricultural products openness will imply reducing its self-sufficiency rate.

Relations among Agric Products Openness, Self-sufficiency Rate and Output Growth Rate. From Eq.4, we obtain

$$
Q_{A}=C_{A} F_{S}-T_{E} F_{S}+O_{P} \cdot F_{S} \cdot Q_{A} .
$$

Eq.5 is static forms of agricultural distribution products. However, the agricultural output growth rate is the change rate of a year and is the concept of dynamic change. Therefore the static agricultural products openness and self-sufficiency rate shall be transformed respectively the dynamic change rate. Differentiating both sides of Eq.5 with respect to time (t), we obtain

$$
\frac{d Q_{A}}{d t}=\frac{d C_{A}}{d t} \cdot F_{S}+\frac{d F_{S}}{d t} \cdot C_{A}-\frac{d T_{E}}{d t} \cdot F_{S}-\frac{d F_{S}}{d t} \cdot T_{E}+\frac{d O_{P}}{d t} \cdot F_{S} \cdot Q_{A}+\frac{d F_{S}}{d t} \cdot O_{P} \cdot Q_{A}+\frac{d Q_{A}}{d t} \cdot O_{P} \cdot F_{S} .
$$

Then get

$$
\left(1-O_{P} \cdot F_{S}\right) \cdot \frac{d Q_{A}}{d t}=\left(\frac{d C_{A}}{d t}-\frac{d T_{E}}{d t}\right) \cdot F_{S}+\left(C_{A}-T_{E}+O_{p} \cdot Q_{A}\right) \cdot \frac{d F_{S}}{d t}+\frac{d O_{p}}{d t} \cdot F_{S} \cdot Q_{A}
$$

Both sides of the above are divided by QA and get

$$
\begin{aligned}
\left(1-O_{P} \cdot F_{S}\right) \cdot \frac{d Q_{A}}{d t} \cdot \frac{1}{\mathrm{Q}_{\mathrm{A}}} & =\left(\frac{d C_{A}}{d t} \cdot \frac{1}{C_{A}} \cdot C_{A} \cdot \frac{F_{S}}{Q_{A}}+H_{1} \cdot \frac{F_{S}}{Q_{A}} \cdot \frac{d F_{S}}{d t} \cdot \frac{1}{F_{S}}\right) \\
& +\left(\frac{d O_{p}}{d t} \cdot \frac{1}{O_{P}} \cdot O_{P} \cdot F_{S}-\frac{d T_{E}}{d t} \cdot \frac{1}{T_{E}} \cdot T_{E} \cdot \frac{F_{S}}{Q_{A}}\right)
\end{aligned}
$$

Definitions: $Q r_{A}=\frac{d Q_{A}}{d t} \cdot \frac{1}{\mathrm{Q}_{\mathrm{A}}}, F r_{s}=\frac{d F_{S}}{d t} \cdot \frac{1}{F_{S}}, O r_{P}=\frac{d O_{p}}{d t} \cdot \frac{1}{O_{P}}, C r_{A}=\frac{d C_{A}}{d t} \cdot \frac{1}{C_{A}}, T r_{E}=\frac{d T_{E}}{d t} \cdot \frac{1}{T_{E}}$.

Where $Q r_{A}$ is the agric output growth rate, $F r_{S}$ the changes rate of self-sufficiency in agricultural products, $O r_{P}$ the change rate of agricultural products openness, $C r_{A}$ the growth rate of agric products in domestic consumption, and $\operatorname{Tr}_{E}$ the growth rate of agricultural exports.

From the composition concepts and Eq.6, it can be determined that the relation between the $Q r_{A}$ and the $F r_{S}$ is approximating linear, so do the relation between the $O r_{P}$ and the $T r_{E}$.If the part of $\left(\frac{d O_{p}}{d t} \cdot \frac{1}{O_{P}} \cdot \frac{O_{P}}{F_{S}}-\frac{d T_{E}}{d t} \cdot \frac{1}{T_{E}} \cdot T_{E} \cdot \frac{F_{S}}{Q_{A}}\right)$ in Eq.6 is assumed to be controlled constant, Eq. 6 reflects the relations among the $C r_{A}$, the $F r_{S}$ and the $Q r_{A}$, in which $C r_{A}$ is mainly determined by consumer behavior; agric output growth is mainly determined by the production function; $F r_{S}$ is not decided by itself law, but is determined by other independent variation together. As can be seen from Eq.6, when the $Q r_{A}$ is higher than the $C r_{A}$, the $F r_{S}$ is positive. On the contrary, it is negative. The net growth rate of agric output $(Q C r)$ is defined as the difference between the $Q r_{A}$ and the $C r_{A}$, the 
following proposition is easy proved.

Proposition 2: The relation between net growth rate of agric output and agricultural products self-sufficiency rate is positively correlated.

From the Eq.6, if the part of $\left(\frac{d C_{A}}{d t} \cdot \frac{1}{C_{A}} \cdot C_{A} \cdot \frac{F_{S}}{Q_{A}}+H_{1} \cdot \frac{F_{S}}{Q_{A}} \cdot \frac{d F_{S}}{d t} \cdot \frac{1}{F_{S}}\right)$ is assumed to be controlled constant, Eq.6 reflects the relations between the $O r_{P}$, the $\operatorname{Tr}_{E}$ and the $Q r_{A}$, in which the $T r_{E}$ is mainly determined by exporting producers behavior; the $O r_{P}$ is not decided by itself law, but is determined by the $\operatorname{Tr}_{E}$ and imports together. In the part of $\left(\frac{d O_{p}}{d t} \cdot \frac{1}{O_{P}} \cdot \frac{O_{P}}{F_{S}}-\frac{d T_{E}}{d t} \cdot \frac{1}{T_{E}} \cdot T_{E} \cdot \frac{F_{S}}{Q_{A}}\right)$, because symbols of the $O r_{P}$ and the $\operatorname{Tr}_{E}$ are opposite, the overall impact on the $Q r_{A}$ is uncertain. As we know the relation between $O r_{P}$ and $\operatorname{Tr}_{E}$ is collinearity, it is uncertain that the $O r_{P}$ impacts on the $Q r_{A}$. The following is obtained.

Proposition 3: The relation between the change rate of agricultural products openness and the output growth rate is uncertain and may be positively correlated, negatively correlated or uncorrelated.

Proposition 3 explains the diversity of views of scholars in the relation between openness and growth. A clear relationship should be determined based on national circumstances. There are comparative advantages and comparative disadvantages between countries, between industries in a country, and also between products inside agriculture. All these relationships can be divided into three categories. Firstly, when agricultural products have a comparative advantage between countries and between industries in a nation, openness will promote not only the absolute growth of agric products but also the economic position of agriculture in a country. Secondly, when agric products own a comparative advantage between countries but not between industries in a country, openness will reduce the proportion of agriculture in a country and promote agric products growth depending on the position of agric products with the comparative advantage. If the output of agricultural products with comparative advantage is greater than the one with comparative disadvantage and the export growth is higher than the import growth, openness will promote agric products growth. On the contrary, it will reduce agric products growth. Thirdly, when agric products do not own a comparative advantage between countries and between industries in a nation, openness will result in the absolute shrinking of agricultural products. Most countries of the world including China belong to the second category.

\section{Summary}

The above mathematical model analysis showed that direct and indirect effect are right. It was well verified by proposition 1 that openness affects the self-sufficiency rate with the direct negative impact way that is higher agricultural products openness will result in lower self-sufficiency rate. The indirect positive effect was well proved by proposition 2 and proposition 3 that is openness raises agricultural products growth to improve self-sufficiency rate. This model will provide theoretical basis for empirical measurement for further research.

\section{Acknowledgements}

Planning Project of "12th Five-Year" in Philosophy and Social Sciences of Guangdong Province, China (Grant No.GD14CYJ05) and (Grant No. GD15XGL23)

\section{References}

[1] H. Ann. Openness and growth: a time-series cross country analysis for developing countries, Journal of Development Economics, 48(1996) 419-447.

[2] E. Leamer. Measuring of openness, trade policy and economic growth, University of Chicago Press, 1988. 
[3] X. F. Huang, Y. Shu. Openness, industrial specialization and China's economic growth, Journal of International Trade, 2007(12) 11-17.

[4] Q.Q. Xiong, S.M.Wen. The index and measurement of China's agricultural openness to the world, Reform, 2012(12) 103-108.

[5] G.Q. Cheng., China agricultural openness: impacts, implications and strategic choice, Chinese Rural Economy, 2012(3) 41-43.

[6] I. Coxhead. Philippine agriculture, food security, and APEC, Asian-Pacific Economic Literature, 2007(2) 50-51.

[7] S.M. Wen, L.J.Zhuang. Analysis on international grain trade patterns and trends, World Agriculture, 2003(6) 25-28.

[8] H.X. Ni. Policy options for China's food security under the conditions of opening up, Issues in Agricultural Economy, 2009(7) 4-8.

[9] Z.C. Sun. International Trade and Agricultural growth, Journal of Shantou University, 2003(4) 1-6.

[10]H. Cao, et al. Research on the balance structure of main agricultural products of China, Macroeconomics, 2013(6) 9-14. 